\title{
Educação Física Escolar na Perspectiva do aluno da Educação Básica: uma Análise a Partir dos Periódicos Nacionais da Área
}

\section{School Physical Education in the Basic Education Student's Perspective: an Analysis from National Area Journals}

\author{
Kerolen Modena Alves*a; Beatriz Teixeira Fernandes ${ }^{\text {a }}$ Patric Paludett Flores ${ }^{\text {b; }}$ Vânia de Fátima Matias de Souza ${ }^{\text {a }}$ \\ Ana Luiza Barbosa Anversa ${ }^{a}$
}

${ }^{a}$ Universidade Estadual de Maringá. PR. Brasil.

bUniversidade Estadual do Paraná. PR, Brasil

*E-mail: kerolenmodena.ka@gmail.com

\begin{abstract}
Resumo
Esta pesquisa teve por objetivo analisar a produção científica (1997-2018) sobre Educação Física escolar na perspectiva do aluno da Educação Básica brasileira. Adotou-se como tipo de pesquisa a revisão integrativa de literatura, sendo feito um levantamento em 14 periódicos científicos da Educação Física sobre o tema. A análise dos dados ocorreu por meio das categorias: perfil dos principais autores com publicação na temática; métodos e instrumentos utilizados nas pesquisas selecionadas e principais temáticas que retratam a perspectiva dos alunos sobre as aulas de Educação Física escolar. Verificou-se que a maior incidência de autores se encontra na região Sul e Sudeste do Brasil. O método mais utilizado nas pesquisas selecionadas foi o qualitativo, tendo como principal instrumento o questionário. Sobre a visão dos alunos a respeito da Educação Física escolar se destacaram concepções positivas, como socialização com colegas e professor; possibilidade de aulas fora da sala de aula; a maneira que o professor realiza a mediação do conteúdo e; como negativas foram identificadas a precariedade na infraestrutura, professores despreparados e/ou desmotivados e resistência dos alunos e professores frente aos novos conteúdos. Diante disso, nota-se que a produção científica analisada indica que os alunos veem as aulas de Educação Física escolar como uma disciplina com poucos conteúdos relevantes, entretanto também traz indicativos de socialização, autonomia e aprendizagem.
\end{abstract}

Palavras-chave: Educação Física. Indicadores de Produção Científica. Discente.

\begin{abstract}
This research aimed to analyze the scientific production (1997-2018) on Physical Education at school from the Brazilian Basic Education student's perspective. The integrative literature review was adopted as a type of research, with a survey carried out in 14 Physical Education scientific journals on the subject. Data analysis took place through the following categories: the main authors' profile with publication on the theme; methods and instruments used in selected research and main themes that portray the students'perspective on school Physical Education classes. It was found that the highest incidence of authors is found in the South and Southeast of Brazil. The most used method in the selected studies was the qualitative one, having as questionnaire the main instrument. Regarding the students' view of school Physical Education, positive concepts stood out, such as socializing with colleagues and teacher; possibility of classes outside the classroom; the way in which the teacher mediates the content and; as negative, the infrastructure precariousness was identified, unprepared and / or unmotivated teachers and students' and teachers'resistance to new content. Therefore, it is noted that the scientific production analyzed indicates that students see school Physical Education classes as a subject with few relevant contents, however it also brings indications of socialization, autonomy and learning.

Keywords: Physical Education. Scientific Publication Indicators. Student.
\end{abstract}

\section{Introdução}

A educação institucionalizada se pauta na formação do sujeito a partir dos indicativos normativos do sistema social vigente nas Instituições de Ensino formal. Segundo Libâneo (2010), as políticas educacionais participam das transformações econômicas, culturais e geográficas que fazem parte da configuração social da atualidade e esses indicadores se refletem na seleção e organização dos conteúdos do ensino formal e na forma com que esses são trabalhados no contexto escolar.

Oliveira, Libâneo e Toschi (2017) apontam que, na atualidade, a escola precisa ampliar os muros institucionais, articulando-se e se integrando com a sociedade de modo a formar cidadãos capazes de pensar e aprender de modo permanente, desenvolvendo conhecimentos, habilidades tecnológicas e atitudes para ser e estar na sociedade de forma autônoma, consciente, crítica, ética e solidária.

A estrutura da Educação Básica brasileira é constituída por diversos componentes curriculares, no entanto, algumas áreas, entre essas a Educação Física, não foram reconhecidas como disciplinas desde seu início no contexto escolar. Por muitos anos, a Educação Física escolar foi encarada como uma atividade curricular, pautada na concepção higienista, militarista e esportivista (OLIVEIRA, 2016).

Apenas em 1980, a área começa a ser pensada por meio de uma perspectiva pedagógica e formativa. Foi a partir da Lei de Diretrizes e Bases da Educação Nacional, Lei no 9.394/1996 (BRASIL, 1996) que a área conquistou a legalidade de seu papel no contexto escolar configurando-se como componente 
curricular obrigatório da Educação Básica (OLIVEIRA, 2016).

Nessa nova perspectiva, a área precisou estruturar seus conhecimentos articulados a um objeto educacional mais amplo, direcionando reflexões para questões sobre o ser e estar na sociedade. De acordo com Henrique (2004), o modo pelo qual o aluno se relaciona com o meio em que está inserido, influencia suas atitudes frente aos estímulos de aprendizagem recebidos, como as formas de apresentação e de problematização das atividades a serem desenvolvidas nas aulas, dando aos conteúdos trabalhados significado e sentido.

Nas aulas deste componente curricular, o aluno deve ser levado a compreender seu corpo, o movimento e suas relações. Para se atingir esse propósito, as aulas de Educação Física escolar precisam ser planejadas e desenvolvidas de modo a tratar de forma pedagógica os conteúdos relacionados à cultura corporal, utilizando-se para isso de preceitos lúdicos, artísticos, estéticos, entre outros (FERREIRA; CASTELLANI FILHO, 2012), dando importância e qualidade às aulas.

Atualmente, os estudos direcionados para a importância e qualidade das aulas de Educação Física escolar são desenvolvidos junto aos professores da área. Darido e Rosário (2005) ressaltam que nas produções científicas são levadas em consideração as perspectivas dos professores quanto à abordagem utilizada por eles em suas aulas e o que trabalham nessas. Em contrapartida, Daniel e Souza (2010) afirmam que a participação e opinião dos alunos sobre as aulas de Educação Física escolar são indicadores que também precisam ser considerados para melhoria das aulas e atendimento dos objetivos pedagógicos traçados, mas o que a produção científica apresenta sobre a perspectiva do aluno sobre as aulas de Educação Física escolar?

Diante disso, estabeleceu-se como objetivo analisar a produção científica (1997-2018) sobre Educação Física escolar na perspectiva do aluno da Educação Básica brasileira.

\section{Desenvolvimento}

\subsection{Metodologia}

Este estudo se caracteriza como uma pesquisa do tipo revisão integrativa de literatura, uma vez que tem como objetivo sintetizar resultados obtidos em pesquisas sobre a temática de modo organizado e abrangente, ampliando a compreensão sobre um determinado assunto ou problema constituído (ERCOLE; MELO; ALCOFORADO, 2014).

Para identificar a produção científica sobre Educação Física escolar na perspectiva do aluno da Educação Básica brasileira, inicialmente, foi realizado um levantamento dos principais periódicos nacionais da área de Educação Física. Como a pesquisa buscou fazer um mapeamento da produção no período de 1997-2018, optou-se por selecionar as revistas classificadas com Qualis B2 ou superior, avaliadas na Plataforma Sucupira no quadriênio 2012-2016.

A partir dos critérios estabelecidos, foram selecionados quatorze periódicos científicos: Movimento; Revista
Brasileira de Medicina do Esporte; Motriz; Revista Brasileira de Ciências do Esporte; Revista Brasileira de Educação Física e Esporte; Journal of Physical Education/Revista da Educação Física - UEM; Motricidade; Revista Brasileira de Cineantropometria e Desempenho Humano; Motrivivência; Pensar a Prática; Licere; Revista Brasileira de Atividade Física e Saúde; Revista Brasileira de Biomecânica e Revista Brasileira de Ciência e Movimento.

Após a seleção dos periódicos foi realizado o levantamento dos artigos pertinentes à temática proposta. Para realizar a busca se utilizou como descritor o termo "Educação Física Escolar". A partir da busca, foram encontrados 1.589 artigos, que foram analisados por dois pesquisadores seguindo critérios de inclusão e exclusão. Para a inclusão foram adotados os seguintes critérios: a) ser artigo original; b) ter sido publicado no período de 1997-2018; e c) trazer a perspectiva do aluno sobre a Educação Física escolar. Foram excluídos os artigos com as seguintes características: a) resenhas; b) artigos de revisão; c) artigos fora do período selecionado de análise; d) artigos que não abordam a Educação Física escolar na perspectiva do aluno; e, f) artigos indisponíveis na íntegra. Após o levantamento e análise das produções, foram selecionados 24 artigos (Figura 1).

Figura 1 - Fluxograma da seleção da produção científica sobre a temática

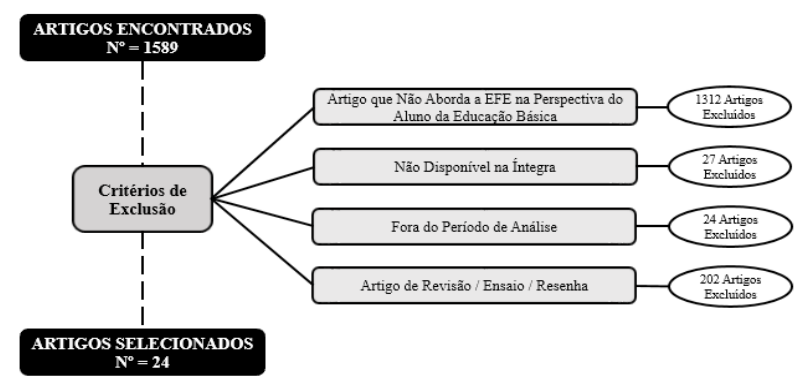

Fonte: os autores.

Após a seleção dos 24 artigos pertinentes à temática e aos critérios de inclusão e exclusão traçados, a análise dos dados ocorreu seguindo o método de Richardson (2012), que propõe a análise por meio de temáticas. A partir da análise dos artigos foram traçadas categorias, a posteriori, para auxiliar na interpretação dos resultados do estudo, sendo essas: Perfil dos principais autores com publicação na temática; Métodos e instrumentos utilizados nos artigos selecionados e principais temáticas que retratam a perspectiva dos alunos sobre as aulas de Educação Física escolar.

\subsection{Resultados e Discussão}

\subsubsection{Perfil dos principais autores com publicação na temática}

Nesta primeira categoria foi identificado o perfil dos principais autores/pesquisadores que estudam a temática da Educação Física escolar na perspectiva do aluno da Educação Básica brasileira, os quais possuem duas ou mais publicações entre os artigos selecionados (Quadro 1). 
Quadro 1 - Perfil dos principais autores com publicação na temática

\begin{tabular}{|c|c|c|c|}
\hline Autor & $\begin{array}{c}\mathbf{N}^{\mathbf{0}} \\
\text { Publicações }\end{array}$ & Instituição & Região \\
\hline $\begin{array}{c}\text { Luciane Cristina } \\
\text { Arantes da Costa }\end{array}$ & 3 & $\begin{array}{c}\text { Universidade } \\
\text { Estadual de } \\
\text { Maringá }\end{array}$ & Sul \\
\hline $\begin{array}{c}\text { Vânia de Fátima } \\
\text { Matias de Souza }\end{array}$ & 3 & $\begin{array}{c}\text { Universidade } \\
\text { Estadual de } \\
\text { Maringá }\end{array}$ & Sul \\
\hline $\begin{array}{c}\text { Lenamar Fiorese } \\
\text { Vieira }\end{array}$ & 2 & $\begin{array}{c}\text { Universidade } \\
\text { Estadual de } \\
\text { Maringá }\end{array}$ & Sul \\
\hline $\begin{array}{c}\text { Ana Luiza } \\
\text { Barbosa Anversa }\end{array}$ & 2 & $\begin{array}{c}\text { Universidade } \\
\text { Estadual } \\
\text { de Maringá } \\
\text { Centro } \\
\text { Universitário } \\
\text { UNIFAMMA }\end{array}$ & Sul \\
\hline $\begin{array}{c}\text { Suraya Cristina } \\
\text { Darido }\end{array}$ & 2 & $\begin{array}{c}\text { Universidade } \\
\text { Estadual } \\
\text { Paulista }\end{array}$ & Sudeste \\
\hline $\begin{array}{c}\text { Sheila Aparecida } \\
\text { Pereira dos } \\
\text { Santos Silva }\end{array}$ & 2 & $\begin{array}{c}\text { Universidade } \\
\text { São Judas } \\
\text { Tadeu }\end{array}$ & Sudeste \\
\hline
\end{tabular}

Fonte: dados da pesquisa.

Nota-se que os pesquisadores com destaque na temática se encontram na Região Sul e Sudeste. Na região Sul foram destacados os nomes dos seguintes pesquisadores: Luciane Cristina Arantes da Costa, com três publicações; Vânia de Fátima Matias de Souza, com três publicações, Ana Luiza Barbosa Anversa, com duas publicações; todas as autoras são membros do Grupo de Estudos e Pesquisas em Educação Física Escolar (GEEFE). Também com duas publicações na temática se destacaram as professoras Lenamar Fiorese Vieira, líder do Grupo de Estudos de Psicologia do Esporte e Desempenho humano (GEPEDH) na Região Sul, e na Região Sudeste Suraya Cristina Darido, líder do Laboratório de estudos e trabalhos pedagógicos em Educação Física (LETPEF) e Sheila Aparecida Pereira dos Santos Silva, membro da Red Latino Americana de Monitoreo y Evaluación e da Rede Brasileira de Monitoramento e Avaliação.

Vale ressaltar que o número de publicações por autor pode estar vinculado com a participação em grupos de pesquisas relativos à temática. Santos (2011) e Matos et al. (2013) trazem que o número de publicações se relaciona com o engajamento de grupos de pesquisa e o apoio financeiro e institucional de agências de fomento. Assim, os grupos de pesquisa que contam com esses investimentos estão classificados como ativos no Diretório de Grupos de Pesquisa (DGP) do Conselho Nacional de Desenvolvimento Científico e Tecnológico (CNPq).

Ao analisar a porcentagem dos grupos de pesquisas relacionadas à Educação Física escolar no DGP, foram constatados o percentual de 48,5\% (16 grupos de pesquisas) na Região Sudeste e 24,2\% ( 8 grupos de pesquisas) na Região Sul do país, essas porcentagens referentes a 100\% (33 grupos) de pesquisas da temática (ANVERSA et al., 2017).
Em contrapartida, no que concerne aos grupos de pesquisas se nota que há poucos grupos (cerca de 20, entre certificados e não certificados), que adotam o termo Educação Física Escolar como nome do grupo/ temática central, entre os registrados no DGP. Isso acontece por meio da dissociação que existe entre os grupos em suas nominologias, por se separarem em educação e Educação Física. Entretanto, a fração de estudos direcionados à Educação Física escolar tem crescido, bem como o interesse entre os pesquisadores (ANVERSA et al., 2017).

Em relação aos Programas de Pós-graduação no Brasil, a Coordenação de Aperfeiçoamento de Pessoal do Nível Superior (CAPES), em 2013, produziu um documento de área, relacionada à área 21 de pesquisa (Educação Física, Fisioterapia, Fonoaudiologia e Terapia Ocupacional), os números obtidos refletiram que as Regiões Sul e Sudeste possuem o maior índice de Cursos de Pós-graduação na área 21 (CAPES, 2013).

\subsubsection{Métodos e instrumentos utilizados nos artigos selecionados}

Em um segundo momento foi realizado um levantamento dos métodos de pesquisa e instrumentos utilizados nos artigos selecionados (Quadro 2).

Quadro 2 - Métodos e instrumentos utilizados nos artigos selecionados

\begin{tabular}{|c|c|c|}
\hline Método f (\%) & Instrumento & $f(\%)$ \\
\hline \multirow{18}{*}{$\begin{array}{l}\text { Qualitativo } 75 \% \\
\text { (f } 18)\end{array}$} & Questionário & $9(26,46 \%)$ \\
\hline & Entrevista aberta & $4(11,76 \%)$ \\
\hline & Entrevista semiestruturada & $2(5,88 \%)$ \\
\hline & Narrativas & $2(5,88 \%)$ \\
\hline & Coleta em banco de dados & $2(5,88 \%)$ \\
\hline & Diário de campo & $3(8,81 \%)$ \\
\hline & $\begin{array}{l}\text { Questionário } \\
\text { semiestruturado }\end{array}$ & $1(2,94 \%)$ \\
\hline & Reuniões & $1(2,94 \%)$ \\
\hline & Fichas de observação & $1(2,94 \%)$ \\
\hline & Fotografias & $1(2,94 \%)$ \\
\hline & Processos de avaliação & $1(2,94 \%)$ \\
\hline & Revisão bibliográfica & $1(2,94 \%)$ \\
\hline & Observação de campo & $1(2,94 \%)$ \\
\hline & Observação dinâmica & $1(2,94 \%)$ \\
\hline & Ilustrações & $1(2,94 \%)$ \\
\hline & $\begin{array}{l}\begin{array}{l}\text { Análise documental em } \\
\text { parâmetros axiológicos }\end{array} \\
\end{array}$ & $1(2,94 \%)$ \\
\hline & Observação participante & $1(2,94 \%)$ \\
\hline & Análise de documentos & $1(2,94 \%)$ \\
\hline $\begin{array}{l}\text { Quantitativo } \\
12,5 \%(f 3) \\
\end{array}$ & Questionários & $3(100 \%)$ \\
\hline \multirow{3}{*}{$\begin{array}{l}\text { Qualiquantitativo } \\
12,5 \%(f 3)\end{array}$} & Questionários & $3(66,7 \%)$ \\
\hline & Diário de campo & $1(16,6 \%)$ \\
\hline & Esquematização das aulas & $1(16,6 \%)$ \\
\hline
\end{tabular}

Fonte: dados da pesquisa.

Foramidentificadosnos artigosouso do método quantitativo descritivo, qualitativo e qualiquantitivo, que por vezes se fez necessário para a descrição, a interpretação e a exposição dos 
resultados obtidos, concedendo maiores informações de dados importantes para a pesquisa (FONSECA, 2002). De acordo com os achados, o método qualitativo se destacou, sendo utilizado por $75 \%$ do total dos artigos analisados. Esse tipo de pesquisa é muito recorrente na área da Educação Física escolar, pois essa temática tem como objetivo estudar "sujeitos, grupos e sociedades de maneira contextualizada, tendo como finalidade a interpretação dos significados de ações humanas, valores, crenças, mitos, construídos culturalmente" (SILVA et al., 2008, p.1), ocorrendo a interpretação do pesquisador sem que haja influência do mesmo no contexto observado.

Das pesquisas de método qualitativo, 26,46\% utilizaram como instrumento de coleta de dados o questionário, por se tratar de um instrumento rápido, barato, de fácil aplicação e grande abrangência (GIL, 2008). Os demais artigos fizeram uso de entrevista aberta $(11,76 \%)$; entrevista semiestruturada $(5,88 \%)$, narrativas $(5,88 \%)$ e coletas em banco de dados (notícias e artigos) (5,88\%); diário de campo (8,81\%) e questionário semiestruturado, reuniões, fichas de observação, fotografias, processos de avaliação, revisão bibliográfica, observação de campo, observação dinâmica, ilustrações, análise documental em parâmetros axiológicos, observação participante e análise de documentos, com 2,94\% cada.

Sobre o método quantitativo, os selecionados adotaram o questionário com questões fechadas. Já os que apresentaram o método qualiquantitativo do tipo descritivo fizeram uso de questionários $(66,67 \%)$; esquematização das aulas $(16,6 \%)$ e diário de campo $(16,6 \%)$.

\subsubsection{Principais temáticas que retratam a perspectiva dos alunos sobre as aulas de Educação Física escolar}

Nessa terceira categoria se destacam as principais temáticas abordadas nos artigos selecionados sobre a perspectiva dos alunos sobre as aulas de Educação Física escolar (Figura 2).

Figura 2- Principais temáticas identificadas nos artigos selecionados

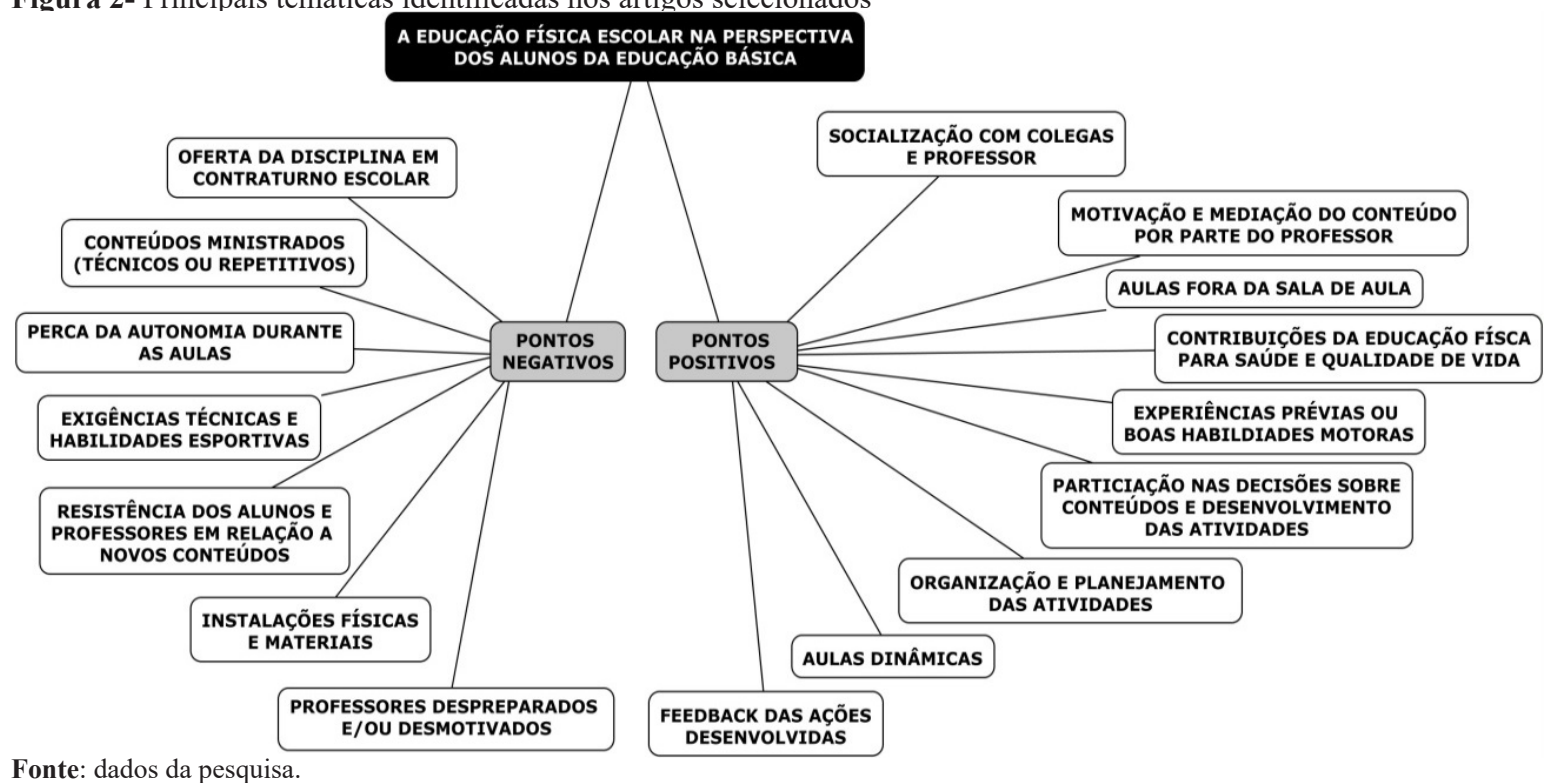

Por intermédio da Figura 2 se pôde constatar que os pontos positivos foram subdivididos em sete aspectos e os pontos negativos em nove. Sobre a temática nomeada como pontos positivos se destaca: 1) socialização com colegas e professor; 2) motivação e mediação do conteúdo por parte do professor; 3 ) aulas fora da sala de aula; 4) contribuições da Educação Física para saúde e qualidade de vida; 5) experiências prévias ou boas habilidades motoras; 6) participação nas decisões sobre conteúdos e desenvolvimento das atividades; 7) organização e planejamento das atividades; 8) aulas dinâmicas e 9) feedback das ações desenvolvidas.

Em relação à temática socialização com colegas e professor se verifica que em relatos apresentados por estudantes adolescentes da $8^{\mathrm{a}}$ série (atual $7^{\circ}$ ano), a maioria declara que considera as aulas de Educação Física um recinto de convívio social, "no qual as relações interpessoais se fazem

necessárias para que esse convívio ocorra harmoniosamente" (CRUZ; FIAMENGHI JUNIOR, 2010, p.427). Essa relação interpessoal é explícita quando questionados sobre o incentivo realizado por esses para com os colegas com a finalidade de estimular o outro em participar das aulas. A grande maioria relata a preocupação da participação dos colegas nas aulas, sendo assim, a participação dos colegas nas aulas é uma decorrência da relação social estabelecida entre esses (CRUZ; FIAMENGHI JUNIOR, 2010).

A socialização existente entre professor/aluno pode ser oriunda e construída de diversos fatores, entre esses as estratégias e práticas metodológicas utilizadas pelo professor, a relação criada com os alunos e a sua comunicação com os mesmos. Esses pontos podem ser essenciais para "contribuir para uma visão positiva do aluno sobre as aulas de Educação Física" (FREITAS et al., 2016, p. 402). Desse modo, a maneira 
pela qual o professor age diante dos seus alunos tem influência sobre suas aulas e suas relações com o alunato.

Já no indicativo motivação e mediação do conteúdo por parte do professor, Menezes e Verenguer (2006) apontam como estratégias motivacionais, os procedimentos metodológicos adotados por professores de Educação Física com o intuito de implantar o aluno no centro do processo de aprendizagem. Ações como um currículo com maior interação e participação dos alunos, em sua execução/elaboração/ opinião, são possíveis permitindo a construção da autonomia dos alunos com escolhas pessoais e conteúdos desejados, influenciando, assim, sua socialização. Além disso, maneiras como diversificação de conteúdos atendem as demandas e necessidades de diferentes alunos. E por fim, a abordagem de temáticas presentes nos dias atuais como beleza, lazer e dieta são maneiras de atrair a atenção dos alunos para as aulas.

No que se referem às aulas fora da sala de aula, os alunos as consideram aulas mais motivantes, em específico nas quadras de esportes. Nas aulas em quadras podem ser trabalhados os conteúdos que os alunos mais gostam, como os esportes, predominantes na grade curricular de Educação Física (FOLLE; TEIXEIRA, 2012).

As contribuições da Educação Física para saúde e qualidade de vida é um dos principais pontos levantados entre os alunos. Essa percepção se origina do senso comum, pelo fato da prática corporal fazer bem para a saúde e ser exposta para a sociedade dessa maneira. Em uma enquete desenvolvida por Darido (2004), os alunos apontaram que praticam atividade física e participam das aulas de Educação Física para melhora da saúde, outros apontam o emagrecimento e o restante do fortalecimento muscular como objetivo a ser alcançado com a prática das aulas. Outrossim, no levantamento de Beggiato e Silva (2007), eles evidenciam os aspectos valorizados pelas turmas relacionados às aulas de Educação Física, os tópicos mais ditos foram exercícios com a finalidade de alcançar bemestar e melhora do condicionamento físico.

Do mesmo modo, a temática, as experiências prévias ou boas habilidades motoras possuem contribuições nas aulas do componente curricular. Vale ressaltar sobre as experiências motoras adquiridas previamente, que estas podem ser classificadas como uma autopercepção de habilidades. Os alunos que praticam alguma atividade/esporte extraescolar apresentam maiores índices de habilidades motoras do que aqueles que não praticam. Contudo, esse nível de habilidade motora tem influência direta na satisfação dos alunos nas aulas de Educação Física. Ademais, de acordo com os fatos: “[...] praticar alguma atividade física ou esporte fora da escola, sugere que esse tipo de experiência também pode contribuir para o aumento da satisfação com a educação física escolar" (BRANDOLIN et al., 2015, p.605).

O sexto indicador foi participação dos alunos nas decisões sobre conteúdos e desenvolvimento das atividades. A colaboração dos alunos do Ensino Médio no planejamento de atividades das aulas de Educação Física gera um índice de satisfação asseverativo, consequentemente, aumentase a vontade de participar das aulas. Assim, a participação ativa dos alunos por meio da visibilidade de suas opiniões é relevante para o desenvolvimento dos mesmos, mediante a esse reconhecimento (BRANDOLIN et al., 2015). O nível de satisfação positivo oriundo da participação na elaboração dos conteúdos do alunato é relacionado para as características da disciplina adquiridas no decorrer dos anos e de seus conteúdos trabalhados (DARIDO, 2001).

Assim como na temática anterior, a conseguinte menciona sobre a organização e planejamento das atividades nas aulas. No levantamento de Souza et al. (2017), relacionado às preferências de conteúdos pelos alunos, observou-se que eles preferem atividades dinâmicas e integrativas, uma vez que por meio dessas a participação é ativa no decorrer do ensino. Além do mais, essa maneira de atrair os alunos pode melhorar "o interesse pelo conteúdo, o que pode resultar em uma possibilidade de uma melhora no aprendizado e na qualidade do ensino" (SOUZA et al., 2017, p. 9). Dessa maneira, é necessário que seja feita uma organização "dos tempos e espaços adequados a cada realidade, considerando as peculiaridades existentes; pois do contrário passa-se a ter a desmotivação e o abandono voluntário do universo escolar" (DANTAS; PAIVA; BARBOSA JR., 2007, p.87).

Com relação à última temática se notam os indicativos para aulas dinâmicas e que tenham feedback das ações desenvolvidas. Com relação às aulas dinâmicas, um projeto interdisciplinar produzido por Souza et al. (2017) se mostrou um maior dinamismo nas aulas. Para os autores, tanto os conteúdos de Educação Física, quanto os de outras disciplinas, foram atrelados à metodologia dos jogos e brincadeiras pedagógicas. Diante dessa estratégia metodológica “obtevese um maior dinamismo para com os conteúdos, o que refletiu em alunos mais interessados e participativos, evidenciando a maior interação entre todos, enaltecendo o trabalho coletivo" (SOUZA et al., 2017, p.10).

Já os feedbacks das ações desenvolvidas nas aulas, os alunos veem que os mesmos contribuem de maneira positiva para os índices de competência desenvolvidos nas aulas de Educação Física (COSTA et al., 2017). No estudo de Mouratidis et al. (2008), o feedback assume duas maneiras de interpretação, a primeira positiva, auxiliando no sentimento de competência e a segunda negativa, quando é utilizado em uma situação de controle, em que o aluno assume um sentimento de frustração.

Para dar sequência na discussão das temáticas da Figura 2, os indicadores pertencentes aos pontos negativos são: 1) oferta da disciplina em contraturno escolar; 2) conteúdos ministrados (técnicos ou repetitivos); 3) perca da autonomia durante as aulas; 4) exigência técnicas e habilidades esportivas; 5) resistência dos alunos e professores em relação aos novos conteúdos; 6) instalações físicas e materiais e 7) professores 
despreparados e/ou desmotivados.

Sobre a oferta da disciplina em contraturno escolar se encontrou que essa é uma característica adotada por algumas escolas, em específico no Ensino Médio, o que acaba gerando desinteresse nos alunos em frequentar as aulas de Educação Física. De acordo com os levantamentos de Cordovil et al. (2015, p.838), os motivos pelo qual levam os alunos a não participação/frequência nas aulas é "a falta de tempo para retornar à escola para fazer Educação Física" e "sou cursante, e não venho à Educação Física". Diante desses relatos é possível constatar que a oferta da disciplina em contraturno escolar contribui para o distanciamento dos alunos, dificultando o processo interdisciplinar, dessa maneira "propiciando o indesejado esvaziamento nas aulas, além de se constituir uma ameaça a sua identidade enquanto componente curricular obrigatório" (CORDOVIL et al., 2015, p.838).

Em relação aos conteúdos ministrados (técnicos ou repetitivos), este se coloca como um dos principais causadores dos desinteresses e desmotivações ocorridos para com as aulas de Educação Física escolar. Freitas et al. (2016) destacam que os alunos relatam a predominância do conteúdo esportes ao longo do ano letivo, dessa maneira a repetição de conteúdo causa desmotivação, pois quando o conteúdo não agrada o aluno este não participa das aulas.

Outro fator negativo presente na perspectiva dos alunos nas aulas de Educação Física está relacionado à perca da autonomia durante as aulas. Segundo Boaventura (2007), a perca da autonomia ocorre mediante a escassez da aprendizagem sistematizada, não desenvolvendo as capacidades necessárias para o aluno seja independente e tome iniciativa frente às ações propostas.

No que diz respeito às exigências técnicas e habilidades esportivas dos alunos nas aulas de Educação Física escolar, Brandolin et al. (2015) apontam que os alunos que possuem alta habilidade esportiva apresentam sete vezes mais chances de estarem satisfeitos com as aulas. Considerando esse índice, as aulas dessa disciplina são designadas, principalmente, para alunos que possuem habilidades corporais e esportivas, desestimulando aqueles que possuem baixo índice de habilidade.

Outro elemento presente na Figura 2 é a resistência dos alunos e professores em relação aos novos conteúdos. Embora existam alunos que desejam conteúdos novos, existem os que encontram resistência para realizá-los, assim como os professores que se sentem desconfortáveis ao saírem da área trabalhada cotidianamente. Diniz, Rodrigues e Darido (2012) ao realizarem uma intervenção com conteúdos novos se deparam, inicialmente, com alunos resistentes, porém no decorrer da aula, eles se sentiram interessados e se demostraram participativos. A resistência inicial, segundo os autores, advém da quebra da rotina desses alunos, acostumados com determinadas ações.

Outro fator que contribui com a negatividade da Educação Física escolar na visão dos alunos são as instalações físicas e materiais disponíveis. Macedo e Antunes (1999) trazem que de acordo com os alunos, a disciplina não é considerada "muito boa", em função da infraestrutura (quadras descobertas), a falta de recursos materiais, e a falta de espaço para serem realizadas as aulas, pelo fato de ter mais professores/aulas de Educação Física ao mesmo tempo.

A última temática retrata os indicativos de professores despreparados e/ou desmotivados. Bento e Ribeiro (2008) salientam que a motivação do professor é um ponto importante para a motivação dos alunos. Isso quer dizer que o professor é um dos responsáveis em criar um ambiente em que os alunos se sintam motivados e satisfeitos com as atividades/aulas propostas.

\section{Conclusão}

A partir da análise da produção científica selecionada foram levantados importantes dados sobre a Educação Física escolar na perspectiva do aluno da Educação Básica. Das produções científicas encontradas se constatou que as regiões brasileiras com o maior índice de publicações, de pesquisadores e de instituições relacionadas à temática foram a Região Sudeste e Sul, ambas ocupam essa colocação em função da quantidade de Grupos de Pesquisas presentes em cada uma dessas.

Relacionado aos instrumentos de coleta de dados presentes nos artigos analisados, constatou-se que a maior parte das pesquisas são norteadas pelos princípios do método qualitativo, utilizando-se do questionário como uma das principais ferramentas de coleta.

Ao analisar as temáticas apresentadas nos artigos que abordam a visão da Educação Física escolar na perspectiva dos alunos, nota-se que o componente curricular apresentou mais pontos positivos do que negativos.

Entre os pontos positivos se destacou a socialização com colegas e professor; a participação nas decisões sobre conteúdos; a possibilidade de aulas fora da sala de aula e a maneira que o professor realiza a mediação do conteúdo. Já sobre os pontos negativos se encontrou que os conteúdos ministrados e as formas como esses são abordados ainda é visto como um fator desmotivacional para os alunos, bem como a resistência de parte dos alunos e professores para com conteúdos novos; a precariedade de infraestrutura e professores despreparados e/ou desmotivados.

Por fim, são destacadas as publicações sobre a temática que trazem um panorama sobre a percepção dos alunos a respeito das aulas de Educação Física em suas potencialidades e fragilidades, elucidando modos de intervir em busca do reconhecimento desta área pelos agentes escolares.

\section{Referências}

ANVERSA, A. L. B. et al. Panorama dos Grupos de Pesquisa em Educação Física Escolar no Brasil. In: CONGRESSO NORTE PARANAENSE DE EDUCAÇÃO FÍSICA ESCOLAR, 8., 2017, Londrina. Anais... Londrina: Universidade Estadual de Londrina. p. 149, 2017. 
BEGGIATO, C.L.; SILVA, S.A.P.S.S. Educação Física Escolar no ciclo II do Ensino Fundamental: aspectos valorizados pelos alunos. Motriz, v.13, n.2, p.29-35, 2007.

BENTO, L.C.M.; RIBEIRO, R.D. As aulas de Educação Física na concepção dos alunos de $5^{\mathrm{a}}$ a $8^{\mathrm{a}}$ séries do Ensino Fundamental da cidade de Indianópolis-MG. Motrivivência, v.20, n.31, p.354368, 2008. doi: https://doi.org/10.5007/2175-8042.2008n31p354

BETTI, M.; LIZ FACCO, M.T. Educação Física escolar: a perspectiva de alunas do Ensino Fundamental. Motriz, v.9, n.3, p.135-142, 2003.

BOAVENTURA, E. Educação física para a autonomia: construção de possibilidades metodológicas. Rio Claro: Universidade Estadual Paulista, 2007.

BRANDÃO, D. Expectativas e importância atribuída à disciplina de Educação Física: estudo comparativo por género nos alunos do $12^{\circ}$ ano de escolaridade nas escolas secundárias do Concelho de V.N. de Gaia. Porto: FCDEF, 2002.

BRANDOLIN, F. et al. A percepção dos alunos sobre a educação física no Ensino Médio. Rev. Educ. Fís. UEM, v.26, n.4, p.601610, 2015. doi: https://doi.org/10.4025/reveducfis.v26i4.29836

BRASIL. Constituição Federal do Brasil. Brasília: Senado, 1988.

BRASIL, Plano Nacional da Educação. Brasília: MEC, 2004.

CAPES, Coordenação de Aperfeiçoamento de Pessoal de Nível Superior Diretoria de Avaliação. Documento de área 2013. Disponível em: https://metadados.capes.gov.br/index.php/ catalog/106/overview?ckan=1. Acesso em: 14 ago. 2020

CORDOVIL, A.P.R. et al. O espaço da educação física na escola: um estudo sobre os conteúdos das aulas no Ensino Médio. Pensar Prática, v.18, n.4, p.834-847, 2015. doi: https://doi.org/10.5216/ rpp.v18i4.34352

COSTA, L.C.A. et al. Educação física e esportes: motivando para a prática cotidiana escolar. Movimento, v.23, n.3, p.935-948, 2017. doi: https://doi.org/10.22456/1982-8918.66430

CRUZ, O.E.; FIAMENGHI JUNIOR, G.A. O significado das aulas de educação física para adolescentes. Motriz, v.16, n.2, p.425-431, 2010. doi: https://doi.org/10.5016/19806574.2010v16n2p425

CURY, C.R.J. A Educação Básica como direito. Cad. Pesq., v.38, n.134, p.293-303, 2008. doi: http://dx.doi.org/10.1590/S010015742008000200002 .

DANIEL, M.M.C.; SOUSA, J.D. Percepção das aulas de educação física na visão de alunos da rede pública de Juazeiro do Norte - CE. In: CONGRESSO DE PESQUISA E INOVAÇÃO DA REDE NORTE NORDESTE DE EDUCAÇÃO TECNOLÓGICA - CONNEPI 2010. Juazeiro do Norte. Anais... Juazeiro do Norte: Instituto Federal de Educação, Ciência e Tecnologia do Ceará, v. 5, n. 1, p.1-6, 2010

DANTAS, M.B.S.; PAIVA, M.O.; BARBOSA JÚNIOR, W.P. O PROEJA no Estado do Rio Grande do Norte: possibilidades e limites. Natal: CEFET, 2007.

DARIDO, S. A educação física na escola e o processo de formação dos não praticantes de atividade física. Revista Brasileira de Educação Física e Esporte, São Paulo, v. 18, n. 1, p. 61-80, jan./mar. 2004. doi: https://doi.org/10.1590/S180755092004000100006

DARIDO, S.C. Os conteúdos da educação física escolar: influências, tendências, dificuldades e possibilidades. Perspect. Educ. Fís. Esc., v.2, n.1, p.5-25, 2001.

DARIDO, S.C.; ROSÁRIO, L.F.R. A sistematização dos conteúdos da educação física na escola: a perspectiva dos professores experientes. Motriz, v.11, n.3, p.167-178, 2005.

DINIZ, I.; RODRIGUES, H.; DARIDO, S.C. Os usos da mídia em aula de Educação Física escolar: possibilidades e dificuldades. Rev. Movimento, v.18, n.3, p.183-202, 2012. doi: https://doi. org/10.22456/1982-8918.27108

ERCOLE, F.F. et al. Revisão integrativa versus revisão sistemática. Rev. Mineira Enferm., v.18, n.1, p.1-260, 2014.

FERREIRA, F.C.; CASTELLANI FILHO, L. Escola e Formação para a cidadania: qual o papel da Educação Física?. Rev. Mov., v.18, n.4, p.135-154, 2012. doi: https://doi.org/10.22456/19828918.31706

FOLLE, A.; TEIXEIRA, F.A. Motivação de escolares das séries finais do Ensino Fundamental nas aulas de Educação Física. Rev. Educ. Fís. UEM, v.23, n.1, 2012. doi: https://doi.org/10.4025/ reveducfis.v23i1.12202.

FONSECA, J.J.S. Metodologia da pesquisa cientifica. Fortaleza: UEC, 2002

FREITAS, J.F. et al. A identidade da educação física escolar sob o olhar dos alunos do $5^{\mathrm{a}}$ ano do Ensino Fundamental I. Pensar a Prática, v.19, n.2, p.396-409, 2016. doi: https://doi.org/10.5216/ rpp.v19i2.39482

GIL, A.C. Métodos e técnicas de pesquisa social. São Paulo: Atlas, 2008.

HENRIQUE, J. Processos mediadores do professor e do aluno: uma abordagem quali-quantitativa do pensamento do professor, da interação pedagógica e das percepções pessoais do aluno na disciplina de Educação Física. Lisboa: FMH, 2004.

LIBÂNEO, J.C. et al. Educação escolar: políticas, estrutura e organização. São Paulo: Cortez, 2012.

MACEDO, R.L.; ANTUNES, R.C.F.S. Valoração da Educação Física: da produção acadêmica ao reconhecimento individual e social. Rev. Pensar a Prática, v. 2, p. 65-83, 1998/1999. doi: https://doi.org/10.5216/rpp.v2i0.150

MATOS, J. M. C. et al. A produção acadêmica sobre conteúdos de ensino na Educação Física escolar. Movimento, v.19, n.2, p.123148, 2013. doi: https://doi.org/10.22456/1982-8918.34213

MATTOS, M.G.; NEIRA, M.G. Educação física na adolescência: construindo o conhecimento na escola. São Paulo: Phorte, 2013.

MENEZES, R.; VERENGUER, R.C.G. Educação física no Ensino Médio: o sucesso de uma proposta segundo os alunos. Rev. Mackenzie Educ. Fís. Esp., v.5, n.3, 99-107, 2006.

MOURATIDIS, A. et al. The motivating role of positive feedback in sport and physical education: evidence for a motivational model. J. Sport Exerc.. Psychol., v.30, n.2, p.240-268, 2008. doi: https://doi.org/10.1123/jsep.30.2.240

OLIVEIRA, A.A.B. La educación física brasileira. puntos débiles y fuertes de su sistema. In: CONGRESO MUNDIAL DEL DEPORTE ESCOLAR, EDUCACIÓN FÍSICA Y PSICOMOTRICIDAD. A Coruña, p.3-5, 2016.

OLIVEIRA, J.F.; LIBÂNEO, J.C.; TOSCHI, M.S. Educação Escolar: políticas, estrutura e organização. São Paulo: Cortez, 2017.

RICHARDSON, R. J. Pesquisa social: métodos e técnicas. São Paulo: Atlas, 2012.

SANTOS, W. A constituição do campo pedagógico do currículo: estratégias, apropriações e circularidades culturais. Vitória: Universidade Federal do Espírito Santo, 2011.

SILVA, C.L. et al. Pesquisa qualitativa em Educação Física: possibilidades de construção de conhecimento a partir do 
referencial cultural. Educ. Rev., n.48, p.37-60, 2008. doi: https:// doi.org/10.1590/S0102-46982008000200003.

SOUZA, V.F.M. et al. Da ação pedagógica à mudança da prática docente: os jogos e as brincadeiras em uma experiência com o Ensino Médio. Pensar a Prática, v.20, n.1, p.3-14, 2017. doi: https://doi.org/10.5216/rpp.v20i1.41125 